\title{
Experimental Studies of Wind Flow Inside a Street Canyon Between High-Rise Buildings with Angle of Attack Modifications
}

\author{
Doni Priambodo ${ }^{\mathrm{a}, 1}$, Yongky Sanjaya ${ }^{\mathrm{a}, 2}$, Prasanti Widyasih Sarli ${ }^{\mathrm{a}, 3}$, Herlien D Setio $^{\mathrm{a}, 4}$ \\ ${ }^{a}$ Civil Engineering Department, Faculty of Civil and Environmental Engineering, Institut Teknologi Bandung, Bandung, Indonesia \\ E-mail: ${ }^{1}$ r.m.doni.p@gmail.com, ${ }^{2}$ yongky.sanjaya94@gmail.com, ${ }^{3}$ pw.sarli@itb.ac.id, ${ }^{4}$ herlien@si.itb.ac.id
}

\begin{abstract}
Failures of smaller structures located in between high-rise buildings due to wind have been observed. Further research on urban wind is needed o prevent further incidents. This research aims to investigate the wind flow in a street canyon of a cluster of 4 simplified symmetrical high-rise buildings with the angle of attack of $0^{\circ}, 30^{\circ}$, and $45^{\circ}$. The study uses Particle Image Velocimeter (PIV) and Low Speed Wind Tunnel for the experiment. The results show that the flow at all angles can be defined as interaction flow, identified by two corner streams at the front passage entrance corner that interacts and merge into a single wide passage jet. The angle of attack changes the pattern of the flow in the cross-area. Before entering the passage, wind-blocking reduces the wind speed up to $40 \%$. After entering the front building passage, its amplification rises to $6.9 \%$ above its original value at the angle of $0^{\circ}$, at the angle $30^{\circ}$, and $45^{\circ}$ after entering it did not increase to its original value; the highest amplification rate occurred at $0^{\circ}$. At the angle of $30^{\circ}$ and $45^{\circ}$, an extremely low wind speed region occurs in the cross area, which did not happen at $0^{\circ}$. It can be concluded that more complex patterns of building clusters lead to more vortex and turbulence in the cross area, which leads to decreasing speed. A "clashing point" from two flows (left and right passage) in its cross-section also leads to a higher turbulence rate in the cross area.
\end{abstract}

Keywords — angle of attack; street canyon; PIV; wind flow pattern; low speed wind tunnel.

\section{INTRODUCTION}

There has been some occasion of failure of smaller structures such as billboard tower in the street canyon between high rise building in Indonesia caused by the change of wind. To prevent a further incident, more research on wind behavior in urban areas are needed. One characteristic that needs investigation is speed amplification factor and flow pattern in a street canyon with different angles. An amplification of windspeed up to $40 \%$ inside street canyons has been observed. That amplification factor is typically attributed to the Venturi effect, meaning that the increase of wind speed is due to the flow section's decrease. Although certain conditions could affect wind behavior differently. In this case, sometimes wind speed also decreases in certain areas affected by wind direction towards the buildings, passage width, buildings arrangement, and building heights. These conditions have been investigated all these years. A study by Stathopoulos and Storms [1] investigates the influence of building heights and different wind directions in the passages. The study observes 6 wind directions $\left(0^{\circ}\right.$ to $\left.90^{\circ}\right)$ while the others azimuth $\left(0^{\circ}\right.$ to $\left.-90^{\circ}\right)$. This study showed that different directions could lead to more vortices and turbulent intensity change in the passage, leading to wind velocity decreasing at certain angles.
Modification of building heights also contributes an upward and downward flow, which affects wind velocity. Further investigation is needed. A study by To and Lam, [2] modified on the configuration of isolated, perpendicular, and along the row of two buildings, the studies shown that in every configuration, the highest wind speed (windiest condition) occurs in the upstream corners.

A study by Blocken et al. [3] modified the model by changing the angle of view of the perpendicular building to the wind's direction coming into a convergent and divergent form. In this study, the diverging passage generally has higher wind speed amplification than the converging passage. It is also shown that decreasing passage width proportional to the increase of maximum wind speed amplification. It should be noted that wind speed within the passages is only pronounced at the pedestrian level. Another study by Blocken et al. [4], observes the effect of wall function by modified the passage width by using CFD. The study showed that pedestrian street level wind could be categorized into three different passage flow patterns: resistance flow, interaction flow, and isolation flow. However, it should be noted that this study only observes a pedestrian level height; whether this phenomenon also happens in higher passage still a mystery. Further investigation is needed. 
A study by Santos et al. [5] observed dispersion behavior from buildings when experiencing wind fluid flow. This research shows the building's wake area when reviewed from the windward direction; there are very low wind speeds with high turbulence intensity. A study by Li et al. [6] modified the model by changing the angle of view of the building to the wind's direction coming into a convergent and divergent form. This study shows that a combination of corner streams mainly determines passage flow. It is also demonstrated that the converging passage does not always amplify the speed. It also has a higher wind-blocking effect than diverging passages explained by lower wind speed and higher drag coefficient.

A study by Allegrini and Lopez [7] shows that building passageway and angle of attack contribute to different wind amplification flow patterns in the street canyon. It shows that converging shaped passage tend to have lower horizontal velocity and higher upward velocity. Meanwhile, diverging shaped flow tends to have higher horizontal velocity and lower upward velocity. However, further investigation is needed. A study by Iqbal and Chan [8] proposed that the configuration with squared central space with prevailing wind direction towards the windward open side face offers a better pedestrian level wind environment because this configuration contains airflow movements more effectively.

A study by Tse et al. [9] observes the effects of twisted wind flows on wind conditions in passages between buildings. It shows that passage width has more significant influences on wind conditions in passages in the twisted wind flows. It shows that twisted wind flows create substantially smaller $\mathrm{k}$ values in wide passages within short buildings than in narrow passages of tall building arrays.

A study by Kuo et al. [10] observe the effects of podium height and approaching wind directions. The study shows that higher podium height contributes to higher wind speed in the street canyon, while lower podium height contributes to lower wind speed. This study also indicates that approaching wind directions to different heights of buildings with podium leads to different wind speed patterns in the street canyon. Other studies about urban wind at the pedestrian level around buildings are reviewed by Mittal and Sharma [11]. These studies show overall subjects needed to understand wind behavior around the buildings such as height and width variation, modification of cross-section, modification along with the height, lift building design, usage of podium structure, different passages between two buildings, the effect of buildings group pattern, and effect of twisted wind flow.

The experimental method used in this study was Particle Image Velocimetry (PIV). A study by Allegrini and Lopez [7] shows that PIV has non-intrusive properties or does not interfere with the wind flow. Besides, this method has high directional sensitivity and spatial resolution. However, this method is not suitable for measuring the boundary layer area and on more complex building clusters. It relies on tracing particle as an observation tool, while tracing the particle is difficult to see in the area around the boundary layer near the building model. Therefore, this method is appropriate to use on a simple model as done in research but not accurate when used for more complex models.
In the past studies, many cases of the understanding angle of attack effects on the building have been done. However, most of the past studies mainly focus on pedestrian level winds ( 1.75 to $2 \mathrm{~m}$ above ground). In contrast, with the many observed failures of pedestrian bridges and billboard towers in vastly developing city landscape, there is a need to understand the behavior of wind at the height of the typical pedestrian bridges (5.1 to $6.5 \mathrm{~m}$ above ground) [12]. While also researching about the angle of attack effect to wind speed behavior. These studies' goals are to understand more about wind mechanism between buildings at pedestrian bridges height and begin with an experimental study.

\section{MATERIAL AND METHOD}

\section{A. Experimental Setup}

The experiments were conducted in a low-speed wind tunnel (LSWT) with a maximum wind speed of $45 \mathrm{~m} / \mathrm{s}$ in Puspitek Research Facility BBTA3, Tangerang, and the wind tunnel length $8.9 \mathrm{~m}$ from intake section to delivery section with a contraction ratio of 9 . This test section length is $1.25 \mathrm{~m}$, with a rectangular cross-section of $0.5 \mathrm{~m} \mathrm{x} 0.5 \mathrm{~m}$ at the inlet becomes a $0.51 \mathrm{~m} \times 0.51 \mathrm{~m}$ at the outtake.

Wind flow above the suburban terrain was simulated with a turbulence intensity of $10 \%$ using spoilers and roughness elements, and a Constant Temperature Anemometer (CTA) was used to observe the resulting flow. Wind speed input from the intake section use a turbulence generator to simulate Atmospheric Boundary Layer (ABL), which approached by power Law equation as shown in the following equation:

$$
U_{z}=U_{r e f} \times\left(\frac{Z}{Z_{\text {ref }}}\right)^{\alpha}
$$

Variable from the equation above defined as speed from observed height $\left(U_{(z)}\right)$, reference speed $\left(U_{\text {ref }}\right)$ from reference height $\left(Z_{r e f}\right)$, observed height $(z)$, and power exponent used in the equation $(\alpha)$.

\section{B. Experimental Model}

In this study, a model of four symmetrical high-rise buildings with the same width, height, and distance was used. The model was observed from three different angles, which consist of $0^{\circ}, 30^{\circ}$, and $45^{\circ}$. Building configurations used in the experiment can be seen in Figure 1.

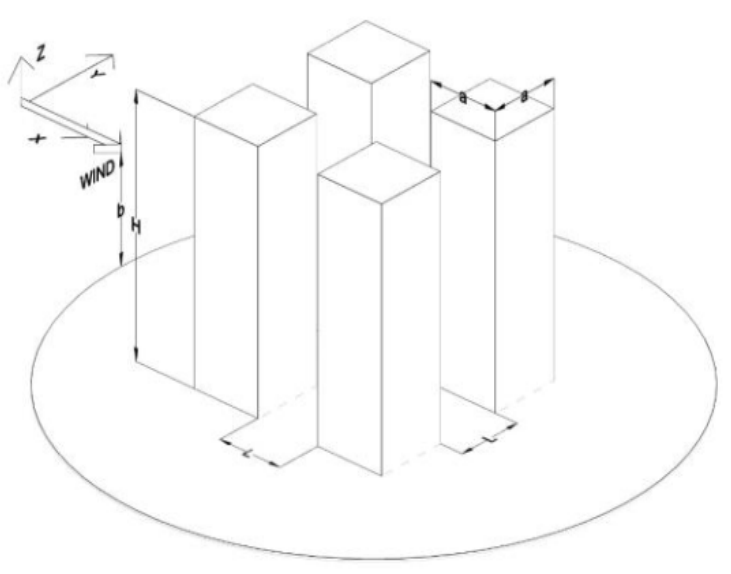

(a) 


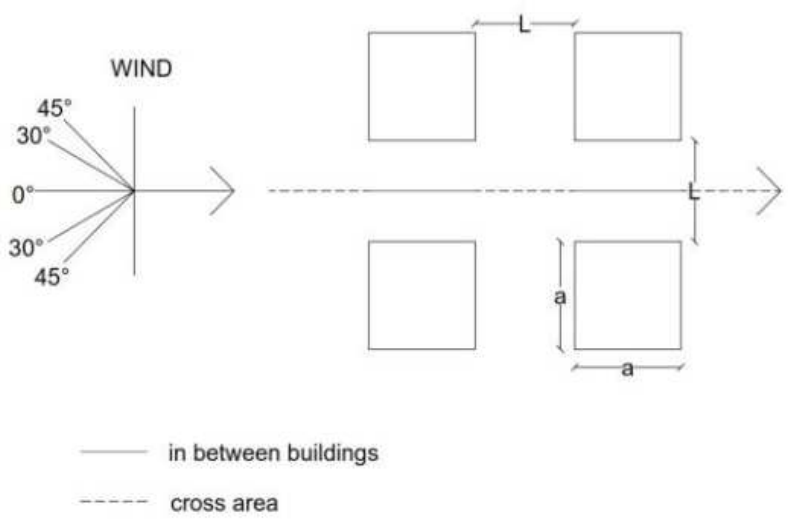

(b)

Fig. 1 (a) 3-D view of schematic of simplified four high-rise buildings configurations, and as (b) seen from above

The models were created with a distance between buildings $\mathrm{L}$ of $70 \mathrm{~m}$ which observed at angle $0^{\circ}, 30^{\circ}$ and $45^{\circ}$. The height of the building is 100 meters, and the width of the building is $32 \mathrm{~m}$. A list of all the different parameters investigated in this study can be seen in Table 1.

TABLE I

LIST OF PARAMETERS USED IN THIS STUDY

\begin{tabular}{|l|l|l|l|}
\hline No & Parameters & \multicolumn{2}{l|}{ Value } \\
\hline 1 & Distance Between Buildings & $L$ & $70 \mathrm{~m}$ \\
\hline 2 & Height of Buildings & $H$ & $100 \mathrm{~m}$ \\
\hline 3 & Width of Buildings & $a$ & $32 \mathrm{~m}$ \\
\hline 4 & Angle of Attack & & $0^{\circ}, 30^{\circ}$, and $45^{\circ}$ \\
\hline 5 & Freestream Wind Speed & $U_{\text {ref }}$ & $15 \mathrm{~m} / \mathrm{s}$ \\
\hline 6 & Freestream Height & $Z_{\text {ref }}$ & $126 \mathrm{~m}$ \\
\hline 7 & Power Exponent & $\alpha$ & 0.28 \\
\hline
\end{tabular}

TABLE II

SCALED PARAMETERS USED IN THIS STUDY

\begin{tabular}{|l|l|l|}
\hline Scaled Parameters & Value & $166.68 \mathrm{~mm}$ \\
\hline $\begin{array}{l}\text { Distance Between } \\
\text { Buildings }\end{array}$ & $\mathrm{L}$ & $238 \mathrm{~mm}$ \\
\hline Height of Buildings & $\mathrm{H}$ & $76.2 \mathrm{~mm}$ \\
\hline Width of Buildings & $a$ & $300 \mathrm{~mm}$ \\
\hline Freestream Height & $Z_{\text {ref }}$ & \\
\hline
\end{tabular}

In this study, the buildings are scaled at $1 / 420$ due to the size of the wind tunnel. However, all the results from the experiments are taken at a normalized value for each wind speed. A list of scaled parameters can be seen in Table 2.

\section{Particle Image Velocimeter (PIV)}

Measurements were taken with a Particle Image Velocimeter (PIV), which is an optical method of flow visualization which used to obtain instantaneous velocity measurement in the flow of the fluid. The fluid with entrained particles is illuminated so that particles are visible. Workflow of PIV can be seen in Figure 2.

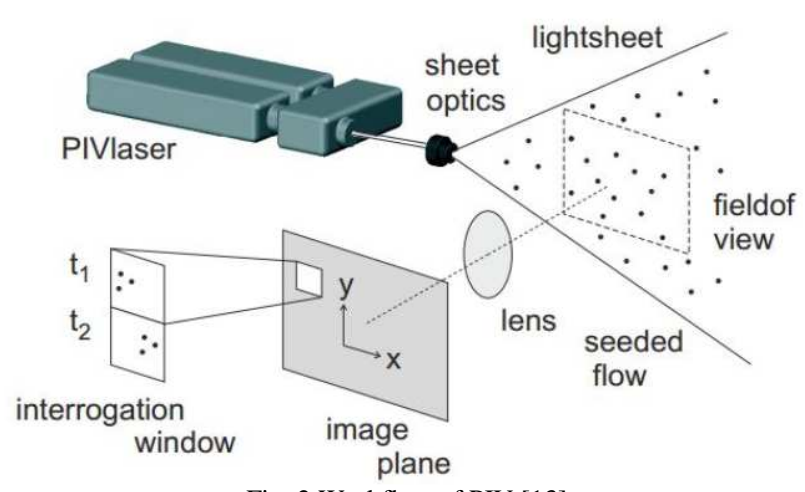

Fig. 2 Workflow of PIV [13]

The basic principle of PIV measurement is by recording photographs of microscopic particles (tracer particles) that move along the fluid flow. Moving particles are illuminated using a laser beam and then recorded using a high-resolution camera (Charge-Coupled Device camera). The recorded image data is divided into small sub-areas (interrogation window). By using the cross-correlation method, local vector displacement particles in each interrogation window can be calculated so that the velocity in the measurement plane of each frame. As long as there are enough particles in the stream being observed, the flow velocity in the laser sheet can be known. A list of PIV parameters used in this study can be seen in Table 3 .

TABLE III

PIV PARAMETERS USED IN THIS STUDY

\begin{tabular}{|l|l|l|}
\hline No & Parameters & Value \\
\hline 1 & $\begin{array}{l}\text { High Speed Camera } \\
\text { Frequency }\end{array}$ & $100 \mathrm{~Hz}$ \\
\hline 2 & Field of View & $400 \mathrm{~mm} \times 300 \mathrm{~mm}$ \\
\hline 3 & Interrogation window & 6464 pixels \\
\hline 4 & Laser light sheet thickness & $2.2 \mathrm{~mm}$ \\
\hline 5 & Tracer particle size & $0.5-1.5 \mu \mathrm{m}$ \\
\hline
\end{tabular}

\section{RESULTS AND DISCUSSION}

\section{A. Boundary Layer Profile}

Power Law equation is used to simulate scaled Atmospheric Boundary Layer (ABL) flow in the test section of wind tunnel. Reference speed $\left(U_{\text {ref }}\right)$ used in this simulation is freestream wind speed of $15 \mathrm{~m} / \mathrm{s}$, reference height $\left(Z_{r e f}\right)$ of $300 \mathrm{~mm}$, and power exponent $(\alpha)$ of 0.28 . Simulated flow used in the experiment can be seen in Figure 3.

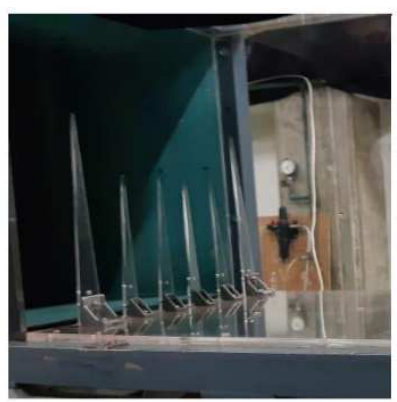

(a) 


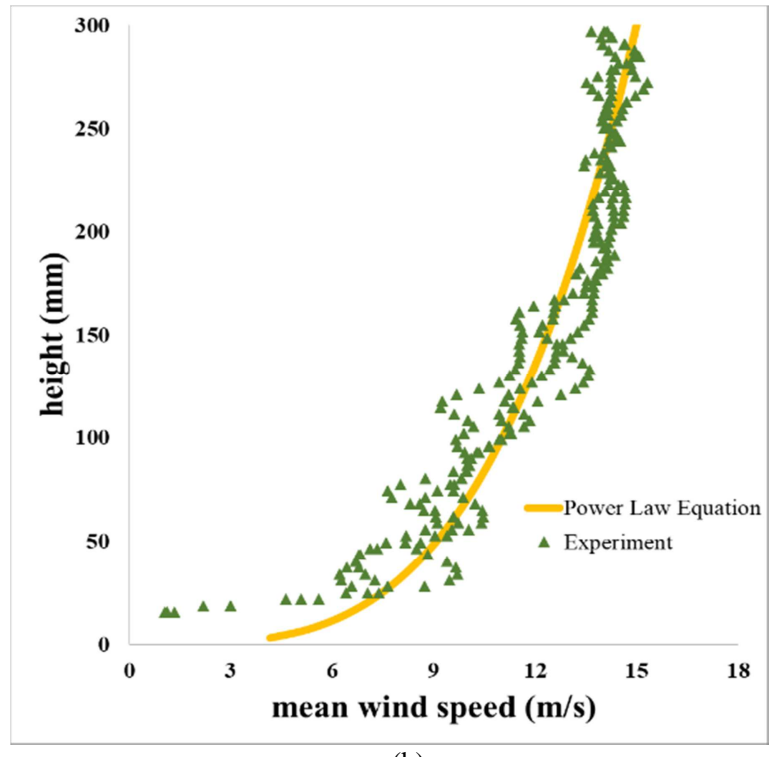

(b)

Fig. 3 (a) Turbulence generator used in the experiment (b) Atmospheric Boundary Layer Profile

From Figure 2, wind speed profile based on power law equation in the test section can be calculated. Observed height in this experiment is $100 \mathrm{~mm}$, mean wind speed at the same height $\left(U_{r e f}\right)$ defined as $11 \mathrm{~m} / \mathrm{s}$ and turbulence intensity of $10 \%$ can be calculated from the flow.

\section{B. Flow Field and Sorting of Disrupted Data}

Results from the PIV captures the flow of the fluid at each grid, where the wind speed and the direction of the vector for the whole time of the fluid flow can be investigated. For each point at the grid the flow of the wind can be observed. Using this data, the effects of angle of attack towards the flow of fluid is investigated. A view of top view and sample of vector field of the experiment at one point in time can be seen in Figure 4.

From top view we can see a shadow line falls from the building. One of PIV's drawback is a susceptibility to light obstruction which can affect the measurement results. To avoid disruption, all data on area covered by shadows are removed. A view of shadow line and sample of obstructed wind speed at one point in time can be seen in Figure 5.

From Figure 5 it can be seen that five shadow lines fall from the building and affect the results by steep jump of wind speed. Therefore, disrupted data in the locations where shadow falls must be removed to avoid miscalculation. After shadow line data is removed, then wind speed can be observed.

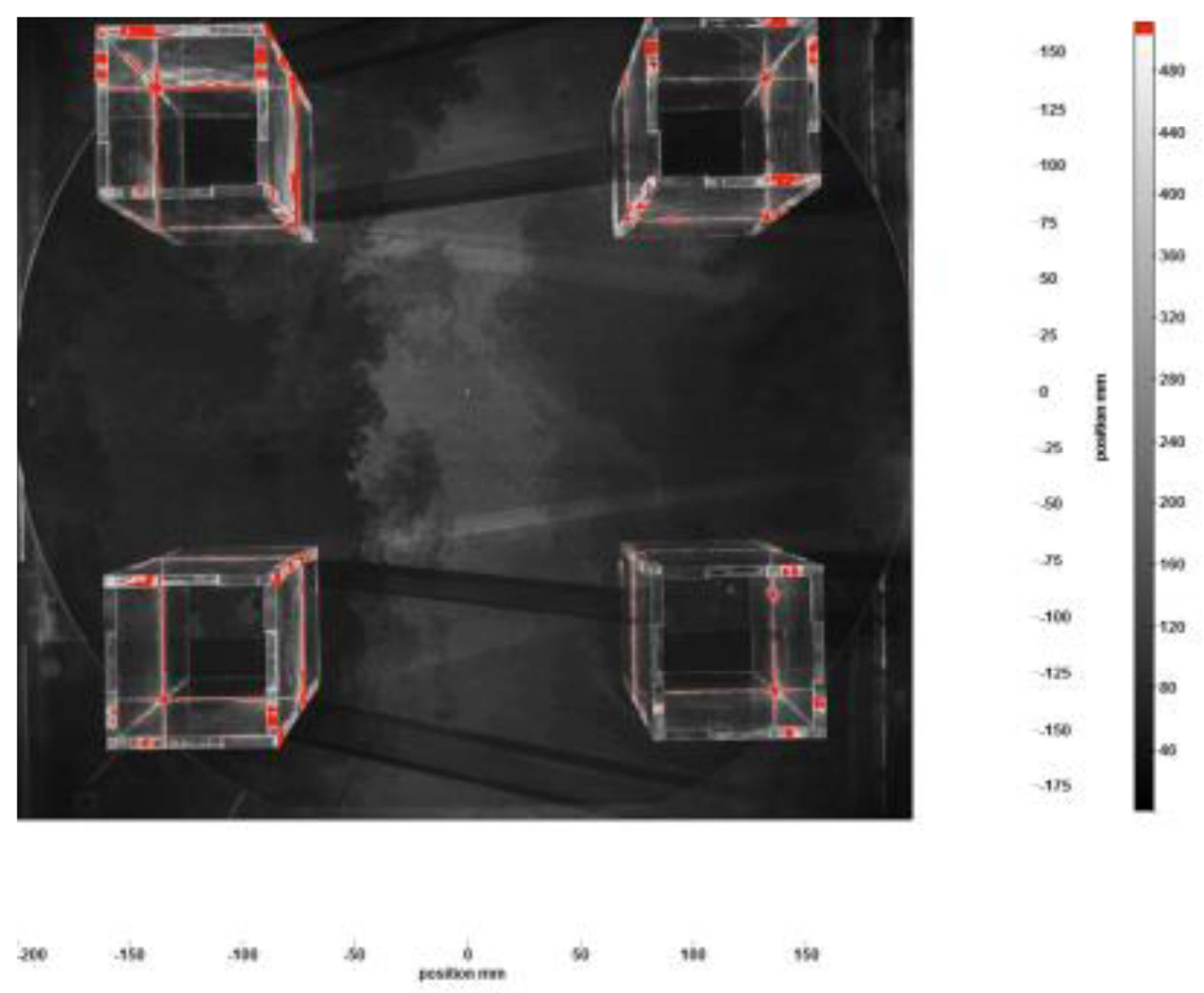



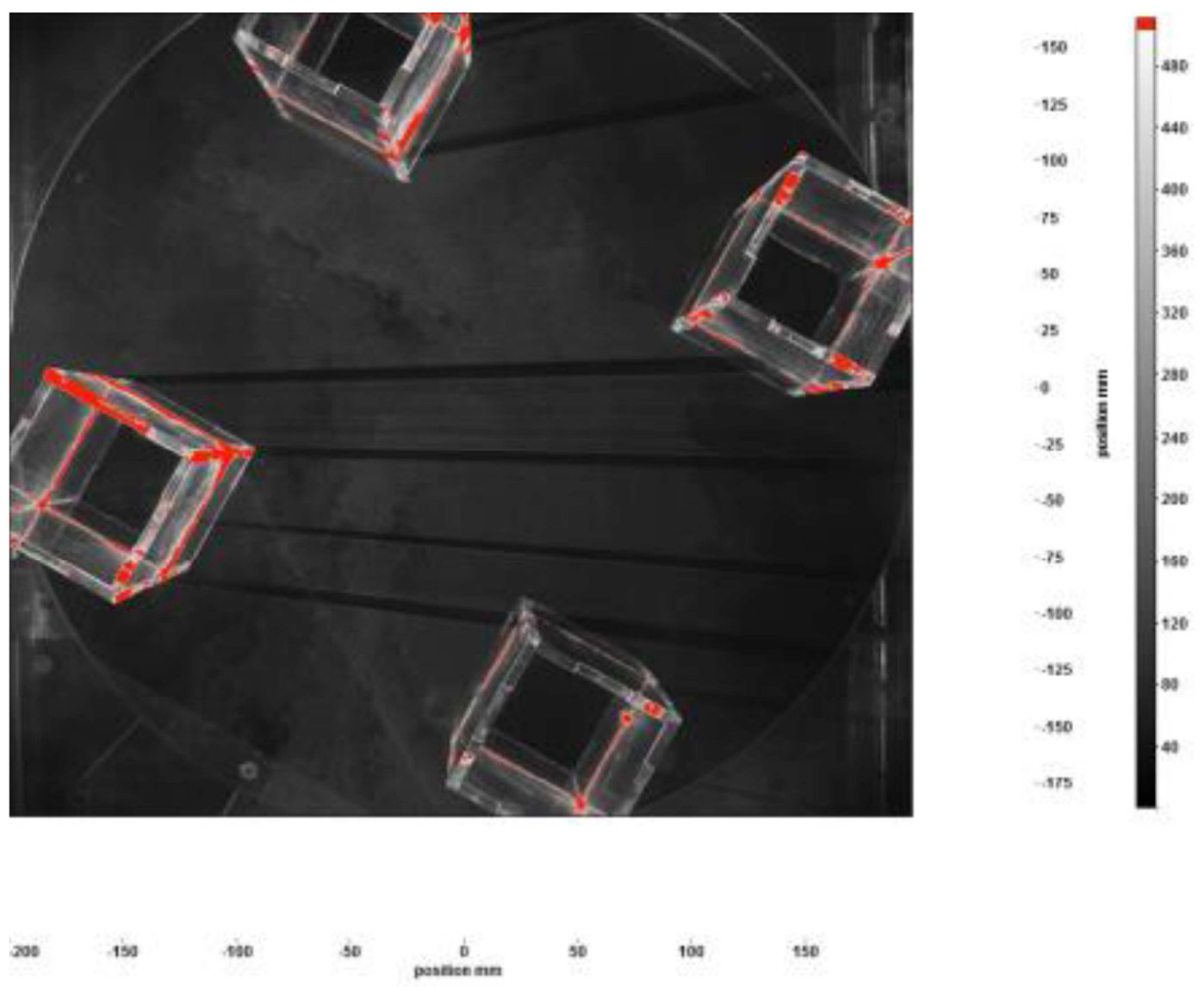

(b)
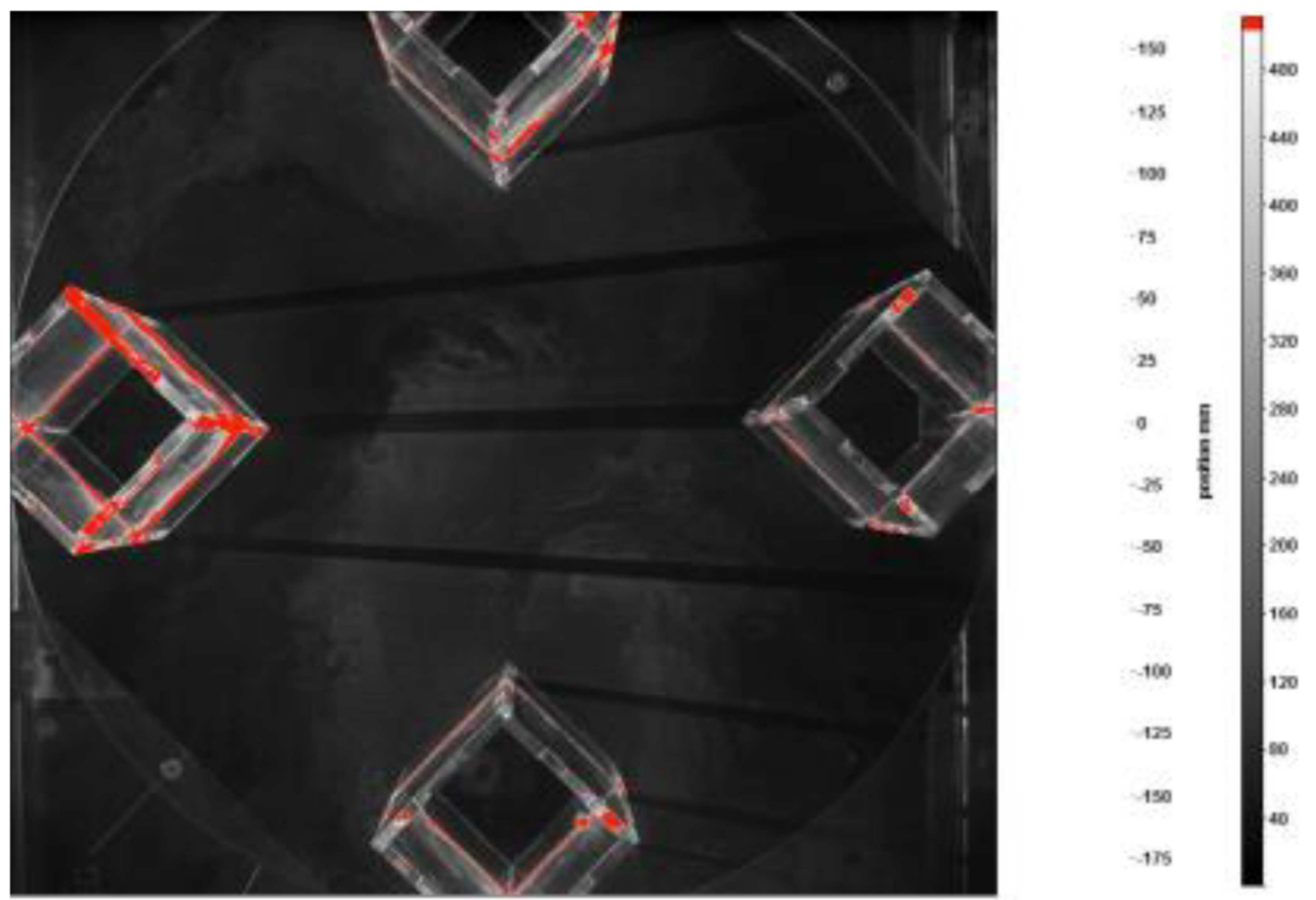

300

iso

sie

so coscoen

50

(c) 


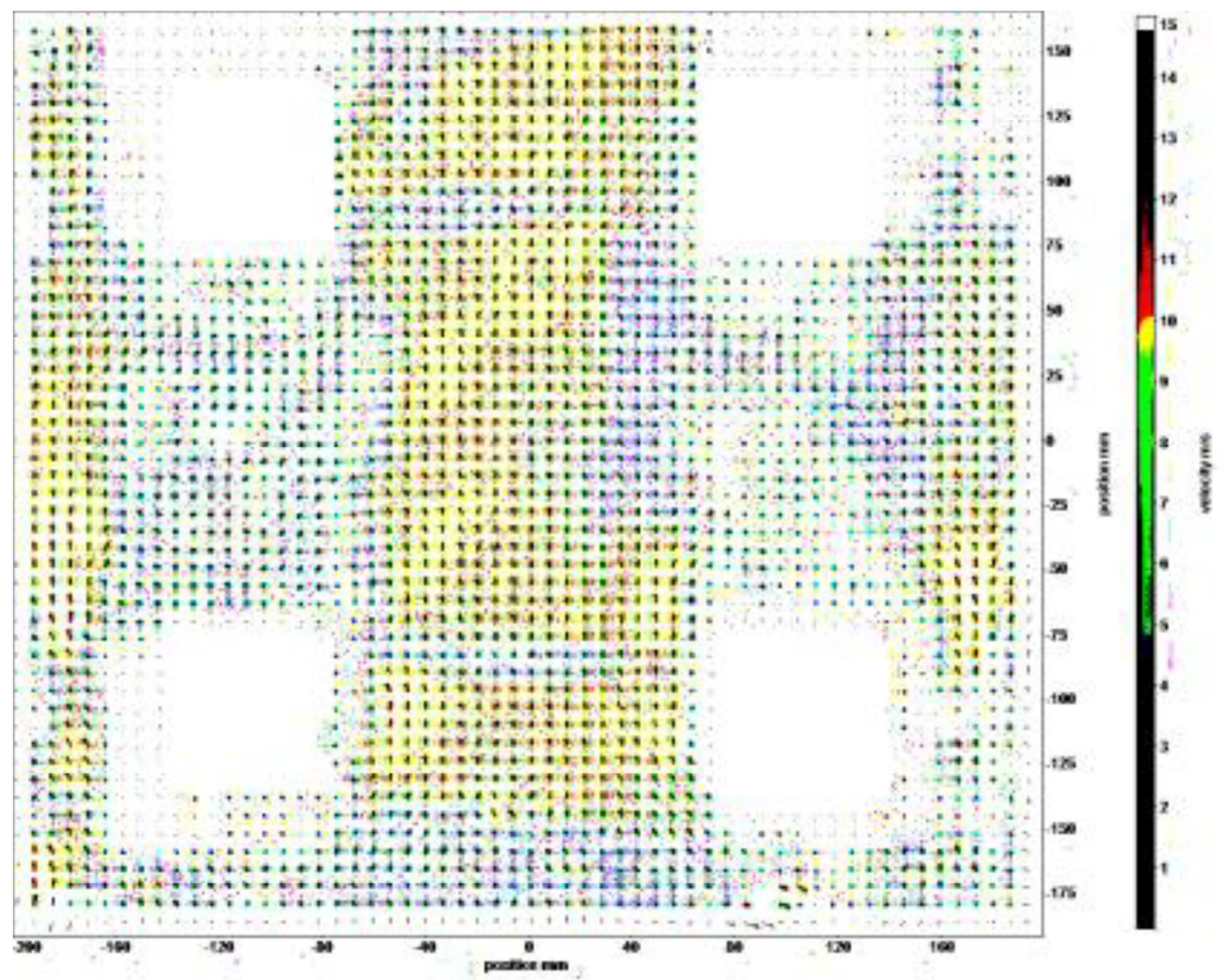

(d)

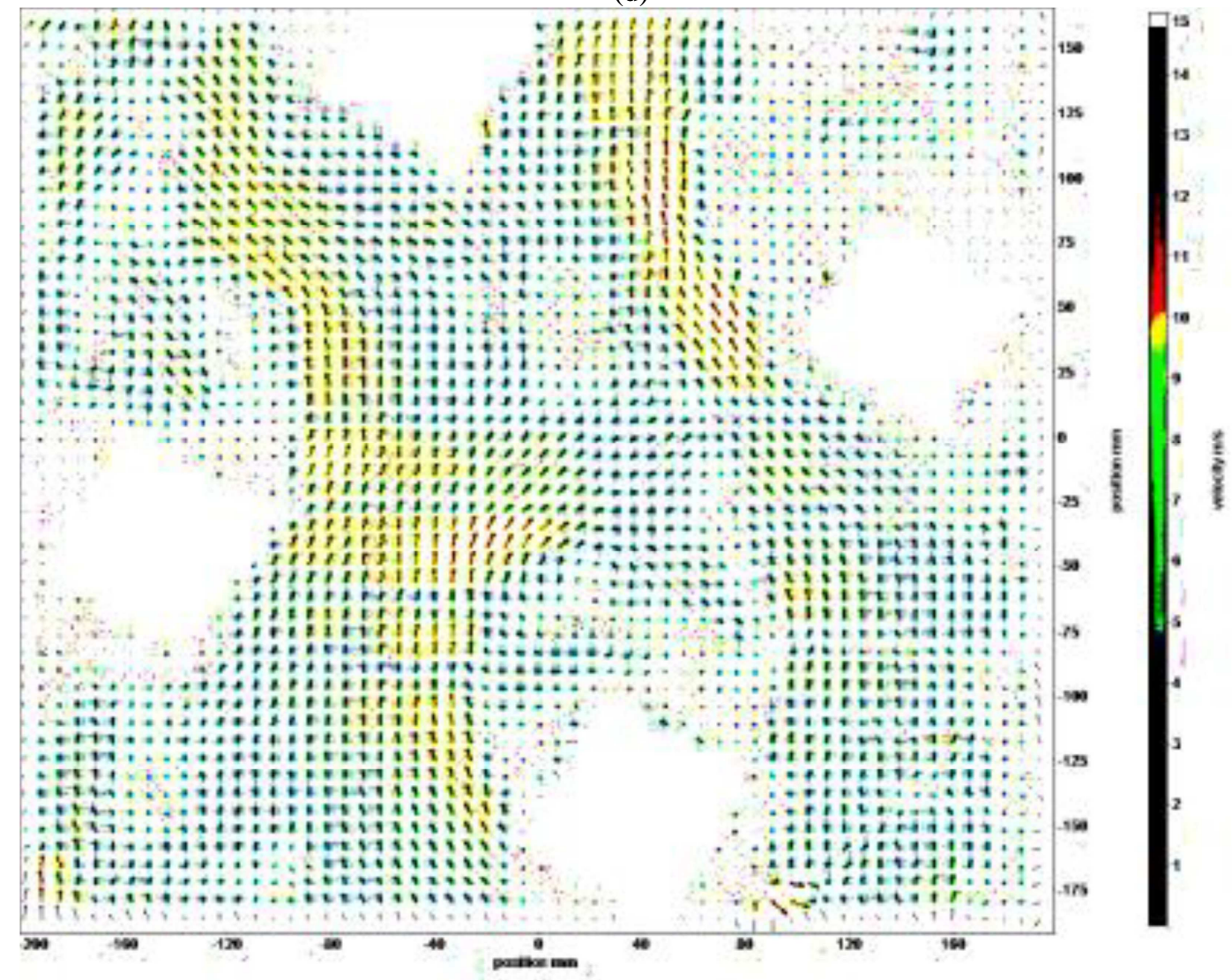

(e) 


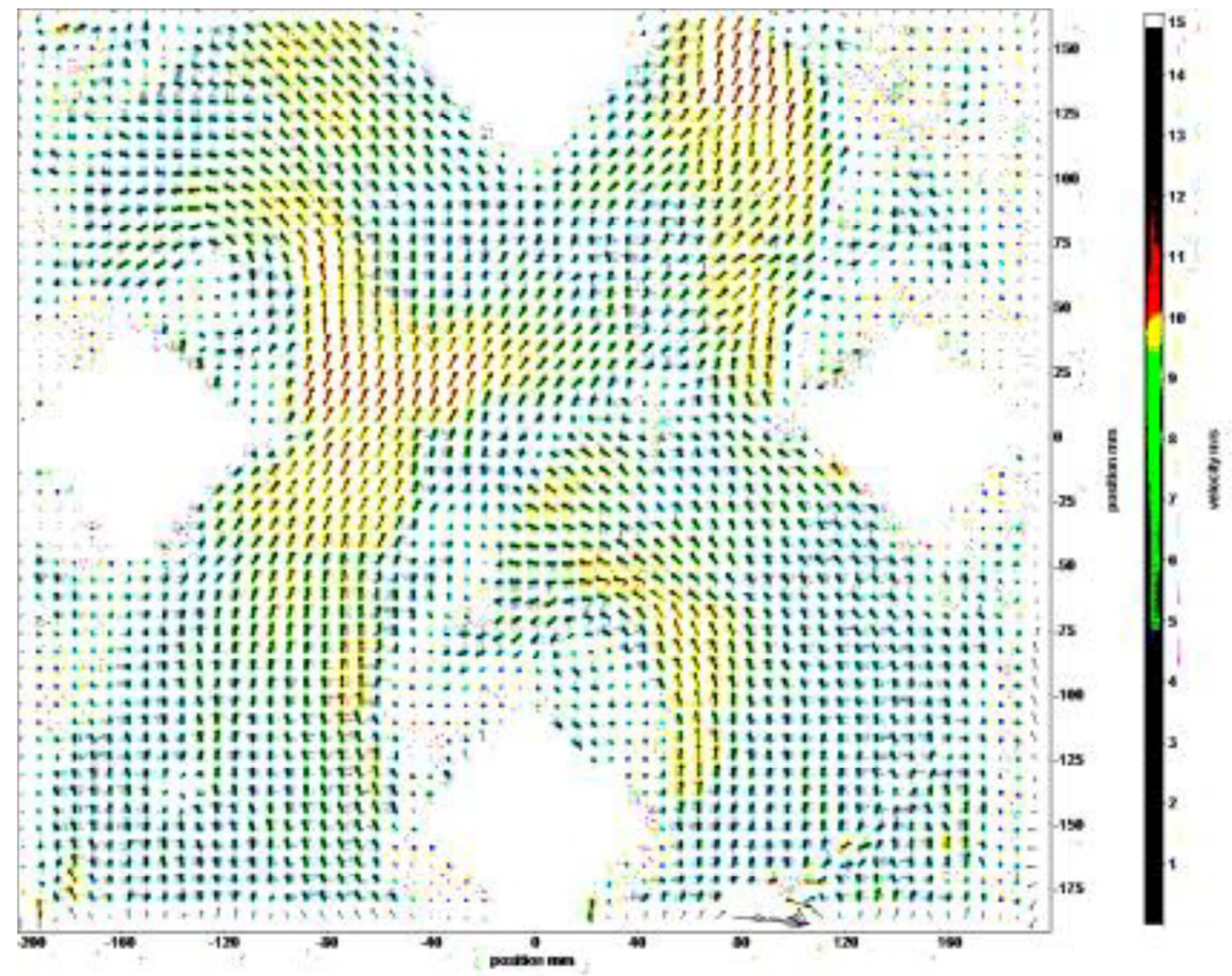

(f)

Fig. 4 Comparison of different angle of attack as captured by the PIV device from top view as captured by camera (a) angle of attack $=0^{\circ}$, (b) angle of attack $=$ $30^{\circ}$, (c) angle of attack $=45^{\circ}$; vector field captured by PIV (d) angle of attack $=0^{\circ}$, (e) angle of attack $=30^{\circ}$, (f) angle of attack $=45^{\circ}$
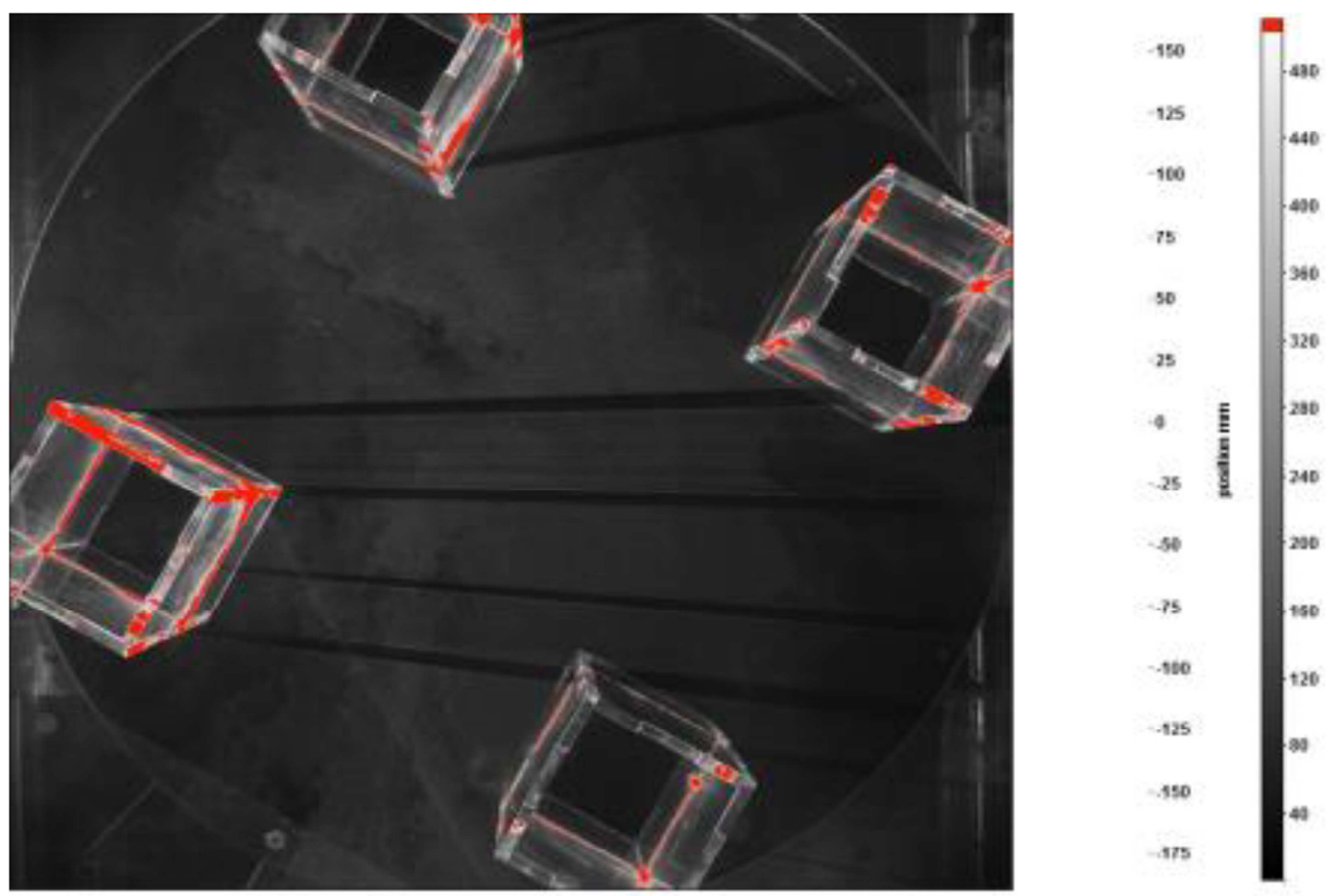

200 


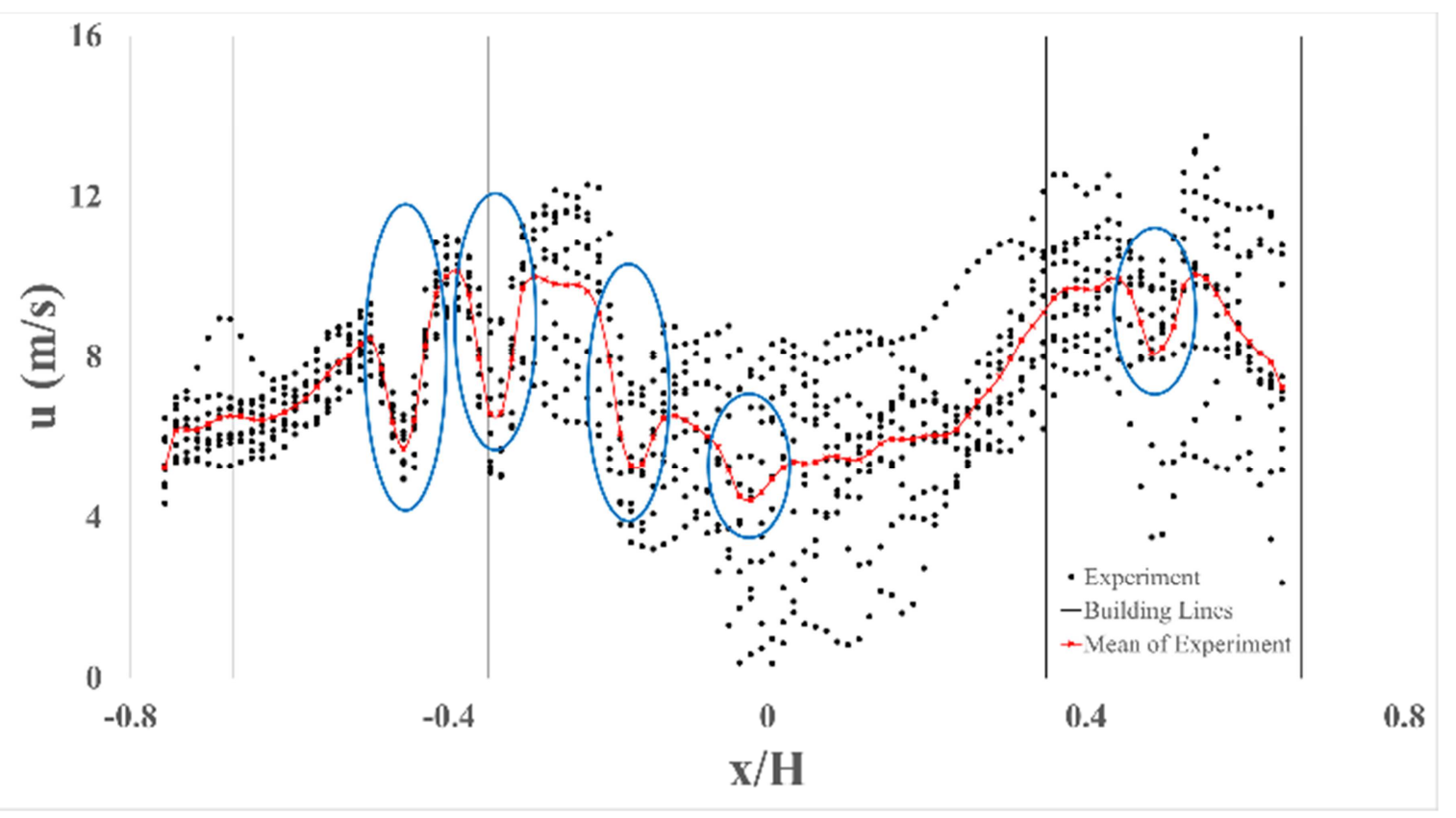

(b)

Fig. 5 Effects of shadow line to data disruption at angle of attack $=30^{\circ}$ (a) top view, (b) normalized experiment results

\section{Analysis of Angle of Attack's Effects}

First let's observe the change of flow from each angle of attack. The flow of wind changes behavior into three different regions, between front buildings, at the cross area, and between rear buildings (see Figure $1 \mathrm{~b}$ for an illustration). In all three regions, there is a fluctuation in wind speed, which differs between each angle of attack. A view of experimental result along the test section can be seen in Figure 6. To simplify the term, ratio of mean wind speed at a certain location between buildings $(U)$, to the mean wind speed at the same location without the buildings being present $\left(U_{r e f}\right)$ is used to categorize a region. In this case, a region which $\left(U / U_{\text {ref }}>1\right)$ is determined as high wind speed region, meanwhile a region which $\left(U / U_{\text {ref }}<1\right)$ is determined as low wind speed region.

From study by Blocken, et al [4], it can be concluded that flow at all angles defined as interaction flow which identified by two corner streams at the front passage entrance corner interact and merge together into single wide passage jet, as the wind speed amplifies while entering the front passage. Although in angle of $30^{\circ}$ and $45^{\circ}$ it behaves differently because of existence of rear buildings and existing flow from second passages which affect the flow in cross area. Further investigation is needed.

Each angle of attack has different flow pattern of peak and trough. It can be observed that angle of $30^{\circ}$ and $45^{\circ}$ have a similar pattern with higher speed between front buildings and rear buildings, and extreme low wind speed region at the cross area. Meanwhile angle of $0^{\circ}$ only have steady speed along its lane. However, it should be noted that high wind speed region almost doesn't happen at all because of wind blocking before entering front buildings passages reduce almost $40 \%$ of the speed before entering the passage $\left(U / U_{\text {ref }}\right.$ $=0.6$ ). This case happens in every angles.

As for the amplifications rate, it only happens a little in the angle of $0^{\circ}$ and does not occur in the angle of $30^{\circ}$ and $45^{\circ}$ which caused by the reduced speed from wind blocking effect before entering the passages. In the angle of $0^{\circ}$, wind speed amplificated from lowest value before entering the passages $\left(U / U_{r e f}=0.6\right)$ up to $6.9 \%$ above its $U_{r e f}$. Meanwhile, in angle $30^{\circ}$ and $45^{\circ}$, amplification did not happen. In these angles, reduced wind speed is not increased enough to reach its $U_{\text {ref }}$. Which means, angle of $0^{\circ}$ produce highest amplification rate between the angles. It can be seen that increased speed always happens while entering front pair of buildings, then it could be steady speed or extremely reduced depends on its angle of attack.

From study by Allegrini and Lopez [7], it can be concluded that buildings cluster at angle $30^{\circ}$ and $45^{\circ}$ forms two converging passage in a region between front buildings which conduce more upward flow caused by the obstruction by front buildings. It also can be seen that it has a "clashing point" from two flows (left and right passage) in its cross section which lead to higher turbulence rate in the cross area (shown by dispersion of wind speed experimentation data) if compared with front passage. Meanwhile rear passage has similar turbulent intensity compared to the cross area.

This phenomenon doesn't occur in a simple non obstructed flow in angle of $0^{\circ}$. Although in angle of $0^{\circ}$, cross area still has higher turbulence intensity than front passage caused by the changing of passage width. Change of maximum turbulent intensity percentage of wind flow between every region at every angle of attack can be seen in Table 4.

TABLE IV

Change Of MAXIMUM TURBULENT INTENSITY

\begin{tabular}{|l|c|c|c|}
\hline Region & Angle 0 $^{\circ}$ & Angle 30 $^{\circ}$ & ${\text { Angle } \mathbf{4 5}^{\circ}}^{\circ}$ \\
\hline Front Passage & $10.61 \%$ & $8.18 \%$ & $15.79 \%$ \\
\hline Cross Area & $14.15 \%$ & $26.2 \%$ & $32.01 \%$ \\
\hline Rear Passage & $19.85 \%$ & $25.09 \%$ & $32.28 \%$ \\
\hline
\end{tabular}




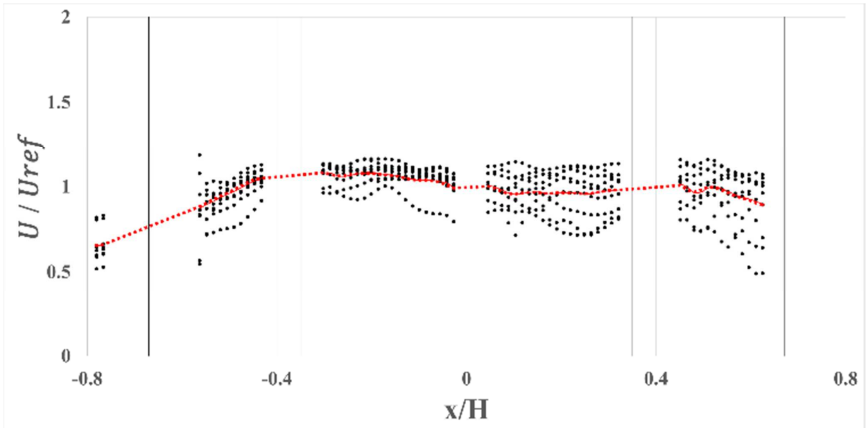

(a)

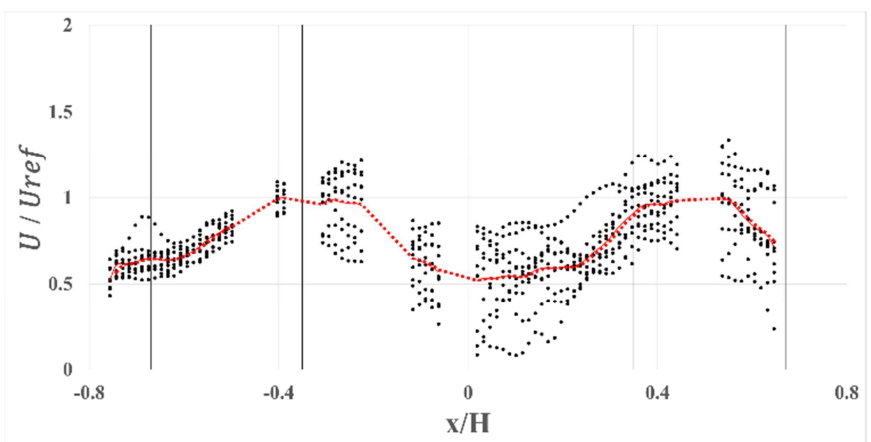

(b)

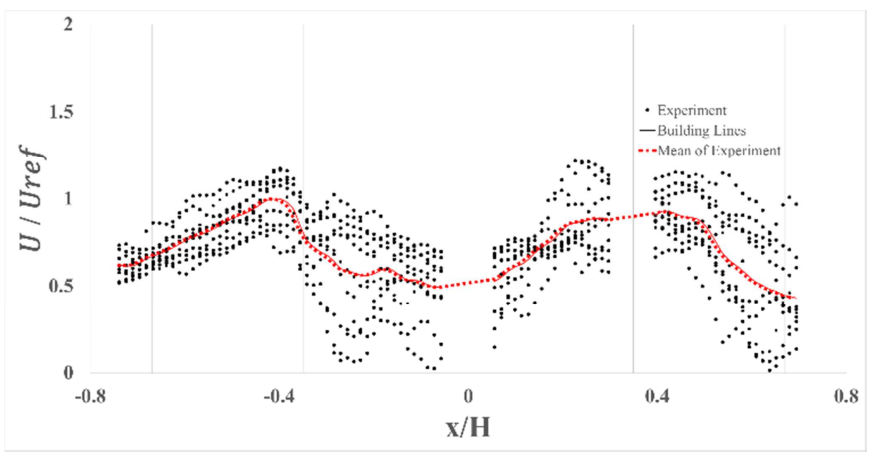

(c)

Fig. 6 Comparison of wind speed from experiment at (a) angle of attack $=0^{\circ}$ (b) angle of attack $=30^{\circ}$ (c) angle of attack $=45^{\circ}$

\section{CONCLUSION}

The behavior of wind between a cluster of 4 high-rise buildings with different angle of attack is investigated. The results show that the flow at all angles can be defined as interaction flow which identified by two corner streams at the front passage entrance corner interact and merge together into single wide passage jet. However, angle of attack modifications on buildings does change the pattern of the flow in the cross-area. Before entering the passage, wind blocking reduces the wind speed up to $40 \%$, then after entering the front building passage, its amplification rises up to $6.9 \%$ above its original value at the angle of $0^{\circ}$, meanwhile at the angle $30^{\circ}$ and $45^{\circ}$ it did not increase enough to reach its original value (amplification did not happen). Which means, angle of $0^{\circ}$ produce highest amplification rate between the angles. It can be observed that at the angle of $30^{\circ}$ and $45^{\circ}$, an extreme low wind speed region occurs in the cross area. Meanwhile angle of $0^{\circ}$ only have steady speed along its lane.
It can be concluded that more complex pattern of buildings cluster lead to more vortex and turbulence (which caused by upward and downward flow) in the cross area which lead to decreasing speed in the cross area. it also can be seen that it has a "clashing point" from two flows (left and right passage) in its cross section which lead to higher turbulence rate in the cross area. Further investigation about this phenomenon is needed in future research. In the next step of the study, a numerical model of this experiment will be investigated. Also, the results from this experiment will later be used to validate numerical Computational Fluid Dynamics models.

\section{ACKNOWLEDGEMENT}

This research is done with the help of the Program Penelitian Pengabdian kepada Masyarakat dan Inovasi ITB (P3MI-ITB) Grant Scheme 2017-2019 from ITB. The experiments were performed in the wind tunnel of BPPTBBTA3.

\section{REFERENCES}

[1] T. Stathopoulos and R. Storms, "Wind environmental conditions in passages between buildings, "Journal of Wind Engineering and Industrial Aerodynamics, vol. 24, pp. 19-31, 1986.

[2] A. To and K. Lam, "Evaluation of pedestrian-level wind environment around a row of tall buildings using a quartile-level wind speed descriptor," Journal of Wind Engineering and Industrial Aerodynamics, vol. 54/55, pp. 527-541, 1995.

[3] B. Blocken, T. Stathopoulos, F. ASCE, and J. Carmeliet, "Wind Environmental Conditions in Passages between Two Long Narrow Perpendicular Buildings," Journal of Aerospace Engineering, vol. 21, pp. 280-287, 2008.

[4] B. Blocken, J. Carmeliet, and T. Stathopoulos, "CFD evaluation of wind speed conditions in passages between parallel buildings-effect of wall function roughness modifications for the atmospheric boundary layer flow," Journal of Wind Engineering and Industrial Aerodynamics, vol. 95, pp. 941-962, 2007.

[5] J. M. Santos, "Numerical simulation of flow and dispersion around an isolated cubical building: The effect of atmospheric stratification." Atmospheric Environment, vol. 43, pp. 5484-5492, 2009.

[6] B. Li, Z. Luo, M. Sandberg, and J. Liu, "Revisiting the 'Venturi effect' in passage ventilation between two non-parallel buildings," Building and Environment, vol. 94, pp. 714-722, 2015.

[7] J. Allegrini and B. Lopez, "The Influence of angular configuration of two buildings on the local wind climate," Journal of Wind Engineering and Indsutrial Aerodynamics, vol. 156, pp. 50-61, 2016.

[8] Q.M. Zahid Iqbal and A.L.S. Chan, "Pedestrian level wind environment assessment around group of high-rise cross-shaped buildings: effect of building shape, separation and orientation", Building and Environment, vol. 101, pp. 45-63, 2016.

[9] K.T. Tse, "Effects of twisted wind flows on wind conditions in passages between buildings", Journal of Wind Engineering and Industrial Aerodynamics, vol. 167, pp. 87-100, 2017.

[10] Kuo, C.Y., Tzeng, C.T., Ho, M.C. \& Lai, C.M., "Wind tunnel studies of a pedestrian-level wind environment in a street canyon between a high-rise building with a podium and low-level attached houses", Energies, vol. 8, pp. 10942-10957, 2015.

[11] Mittal, H. \& Sharma, A., A review on the study of urban wind at pedestrian level around buildings. Journal of Building Engineering, pp. 154-163. 2018.

[12] D. J. B. M. Kementerian PUPR and D. B. Teknik, "Tata Cara Perencanaan Jembatan Penyebrangan untuk Pejalan Kaki di Perkotaan," Kementerian PUPR, Direktorat Jendral Bina Marga; Direktorat Bina Teknik, vol. Jembatan, No. 027/T/Bt/1995.

[13] BBTA3.TR.20.0002.R, "Laporan Kajian Aerodinamika Model Gedung Menggunakan PIV di ESWT,” 2020. 